\title{
Performance Comparison of Mobile Ad Hoc Network Routing Protocol and Transmission Control Protocol
}

\author{
Akinwole A. K. ${ }^{1}$ \& Emuoyibofarhe O. J. ${ }^{2}$ \\ ${ }^{1}$ Department of Computer Technology, Yaba College of Technology, Lagos State, Nigeria \\ ${ }^{2}$ Department of Computer Science and Engineering, Ladoke Akintola University, Ogbomosho, Nigeria \\ Correspondence: Emuoyibofarhe O. J., Department of Computer Science and Engineering, Ladoke Akintola \\ University, Ogbomosho, Oyo State, Nigeria. E-mail: agnesskike2006@yahoo.com
}

Received: March 26, 2012 Accepted: April 5, 2012 Online Published: June 12, 2012

doi:10.5539/cis.v5n4p102 URL: http://dx.doi.org/10.5539/cis.v5n4p102

\begin{abstract}
In this work the Performance Comparison of Mobile Ad Hoc Network (MANET) Routing Protocols and Transmission Control Protocol (TCP) was investigated in order to evaluate the performance of Routing Protocols (AODV, DSR and TORA) and TCP (Tahoe, Reno and New Reno). The Model that represented the hypothetical network was developed and simulated using OMNet++4.1.

The three Routing protocols were tested upon each of the three variants of Transmission Control Protocol. End to end throughput was the performance parameter (metric) used for the evaluation of Routing protocols and TCP performance.
\end{abstract}

Keywords: MANET, TCP, routing protocol

\section{Introduction}

Mobile ad hoc network (MANET) is a famous ad hoc network that can be utilized well for emergency situation and military applications. It is useful in disaster recovery situations and places with non-existing or damaged communication infrastructure where rapid deployment of a communication network is needed. It can also be useful on conferences where people participating in the conference can form a temporary network without engaging the services of any pre-existing network (Larsson \& Hedman, 1998).

Routing Protocol is a standard that specifies how nodes communicate with each other, disseminating information that enables them to select routes between any two nodes on a computer, the choice of the route being done by the routing algorithms. Each router has a priori knowledge only of networks attached to it directly. A routing protocol shares this information first among immediate neighbours, and then throughout the network. This way routers gain knowledge of the topology of the network.

Transmission Control Protocol (TCP) sometimes called Transfer Control Protocol is one of the core protocols of the Internet Protocol suite, and one of the two original components of the suite complementing the Internet Protocol (IP), and therefore the entire suite is commonly referred to as TCP/IP. TCP provides reliable ordered delivery of a stream of bytes from a program on one computer to another program on another computer.

\section{Related Works}

Recently many researches had been carried out on Performance Comparison of MANET Routing Protocol and Transmission Control Protocol; some of the researches include the following:

i. Routing Protocols in Wireless Ad Hoc Networks - A Simulation Study (Larson \& Hedman, 1998): This study compared the performance of three routing protocols namely: DSDV, AODV, and DSR. The three routing protocols were simulated using Network simulator 2. The performance of the routing protocols was evaluated using the following metrics: Fractions of received packets, end to end delay, end to end throughput, overhead, optimal path against the following parameters: mobility, offered network load, and network size. The results of the simulation showed that AODV and DSR had overall exhibited good performance. Also, a combination of AODV and DSR was suggested that could be a solution with even better performance.

ii. Transmission Control Protocol (TCP) Performance Evaluation in MANET (Ijaz, 2009): Three TCP namely: New Reno, Reno and Reno and three MANET routing protocols namely: AODV, DSR and TORA were 
considered and simulated using OPNET (Optimized Network Evaluation Tool) modeller version 14.5. The metrics used for the evaluation were: delay, throughput and congestion window and were measured against the network size ( 3 nodes, 5 nodes and 8 nodes). The simulation observation clearly described the evaluation through measuring throughput, delay and congestion window that the best routing protocol for MANET is AODV.

\section{The Model}

The model comprises of network nodes which were modelled as a collection of modules (a module can be simple or compound). The model was used for simulating selected MANET routing protocols (Ad Hoc on Demand distance Vector, Dynamic Source Routing, and Temporally Ordered Routing Algorithm) on variants of TCP (Tahoe, Reno and New Reno). The implementation of AODV, DSR, Tahoe, Reno, and New Reno was based on the inetmanet library developed for OMNeT++. TORA routing protocol was implemented based on interfaces and standards defined in inetmanet and IETF draft "draft-ietf-manet tora-spec".

The Model (as shown in Figure 1) comprised numclients, Channelcontrol and Networkconfigurator. Numclients were nodes that were trying to communicate with another node that acts as the server. These nodes moved randomly within an area of specified width $(700 \mathrm{~m})$ and length $(500 \mathrm{~m})$. Channelcontrol contained information about the location and movement of nodes and determined which nodes were within communication or interference distance. Network Configurator configured the IP addresses and the routing tables for the network.

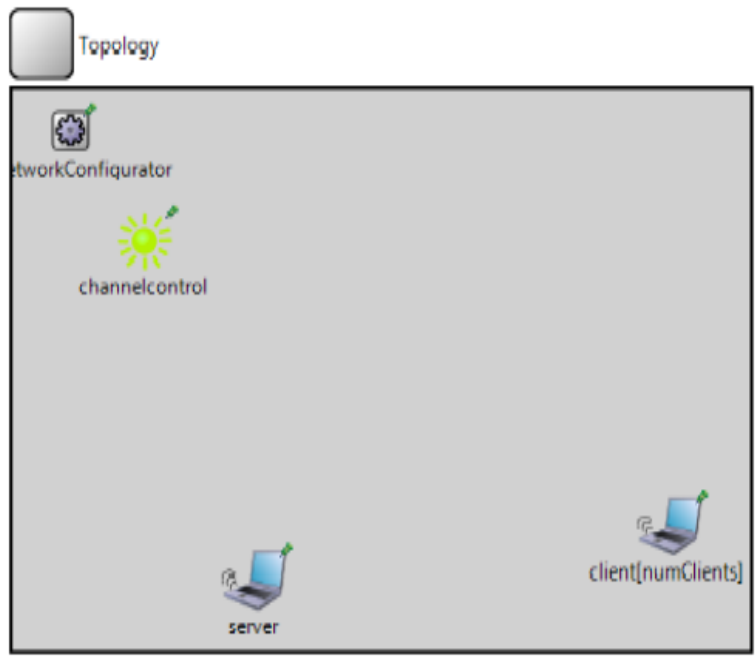

Figure 1. The network model

Figure 2 showed the components in each node. In each of the client nodes was a TCP application that downloaded a file from the server. The TCP application on the server received connections from client nodes and sent the files requested. Other relevant modules in the diagram include:

i. Manetrouting: this module performed MANET routing based on specified routing protocol. It contained a ManetManager which initiated the requested routing protocol.

ii. interfaceTable: held information about the network interfaces in the node. A loop adapter interface was added by default together with other network interfaces present (in this case, the wlan module which represented the wireless NIC of the node).

iii. Pingapp: this generated ping requests and calculate the packet loss and round trip parameter of the replies. Every ping request was sent out with a sequence number and reply was expected to arrive in the same order.

iv. TCP: represented the TCP layer, the TCP module is configured to use any of the three selected algorithms based on the simulation scenario.

v. UDP: this is user datagram protocol, is a simple OSI transport layer protocol for client/server network application based on Internet protocol.

vi. Networklayer: this is a compound module representing the Network Layer of the OSI network stack. It constituted errorhandling, icmp, igmp, ip and arp. ICMP (models ICMP protocol) means Internet Control 
Message Protocol and it was used to perform network error reporting and status. IGMP (models IGMP protocol) is Internet Group Management Protocol it was used for multicasting that is to send message to groups of nodes. ARP (model ARP protocol) is Address Resolution Protocol and it was used to translate IP-addresses to hardware MAC addresses. This takes place before the packets are sent down to the MAC layer. Figure 3 showed the constituent components of the module.

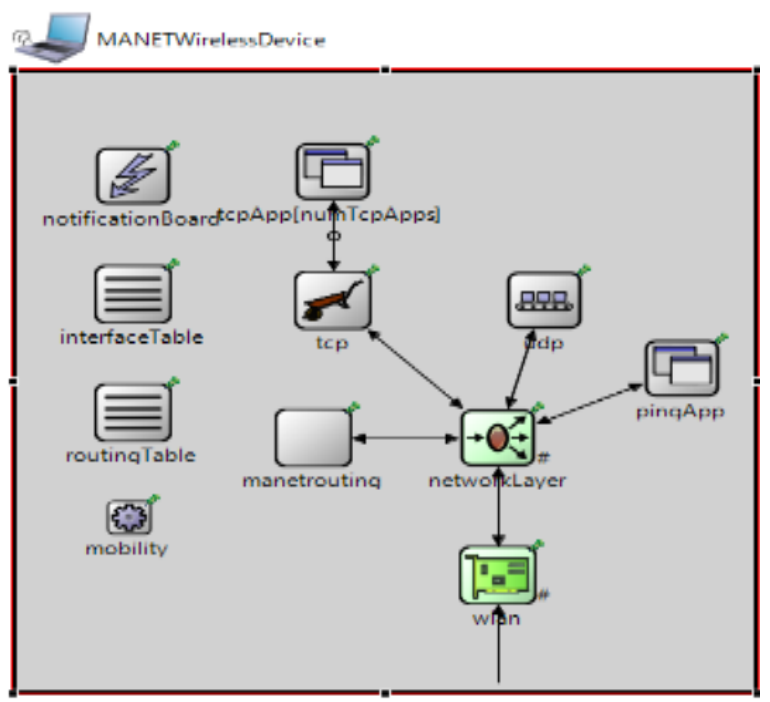

Figure 2. Components in a Node
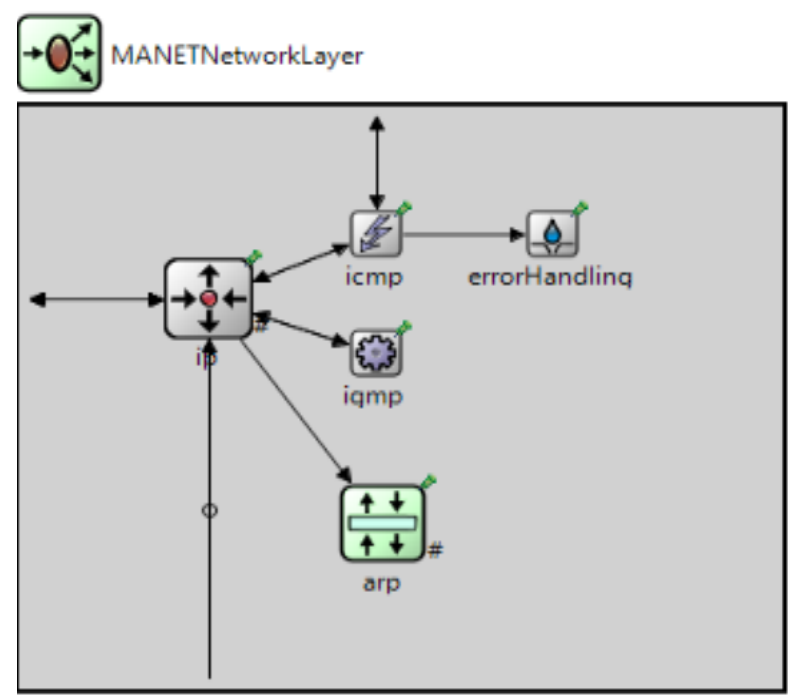

Figure 3. The network layer module

vii. routingTable: this represents the routing table in the node. It was used by the manetrouting module to process and store information. The IP module also used it to identify a route to a required destination.

viii. mobility: this component manages the mobility of the node. It was in charge of determining the location of a node in the playground in the course of the simulation. It modelled different kinds of mobility like mass mobility, random mobility linear mobility, and constant speed mobility e.t.c.

ix. WLAN: this module represented the wireless NIC on the node. It was a compound module comprising of the radio, mac and management components as shown in Figure 5. It represented the IEEE802.11 wireless NIC in Ad Hoc mode.

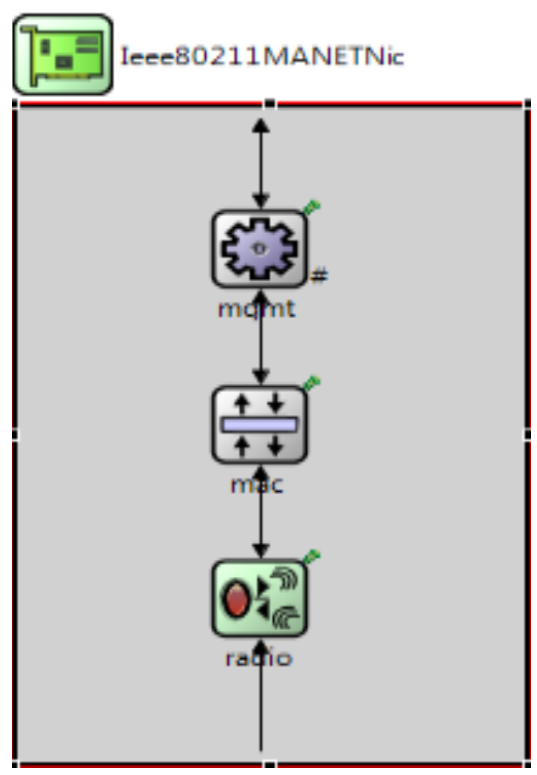

Figure 4. The WLAN module 
x. NotificationBoard: this component performed registry functions it was used by components to publish their state and send notification to other interested components.

\section{The Simulation}

Having developed the model, the next step was to perform simulation with different parameters. For the simulation, the TCP application in client nodes attempted to download a file of size $1 \mathrm{MB}$ from the server. In the course of the simulation, the performance parameter that is end to end throughput (in KBps) was recorded. The performance parameter was measured against:

i. Number of clients (network size): five, ten and fifteen clients were considered

ii. Routing Protocol: Dynamic Source Routing(DSR), Ad Hoc On-Demand distance Vector Routing (AODV) and Temporally Ordered Routing Algorithm (TORA)

iii. Transmission Control protocol (TCP) Algorithm: Tahoe, Reno, and New Reno

\subsection{Simulation Scenarios}

The Scenarios consisted of nodes (5 clients, 10 clients, and 15 clients were used for the simulations) placed randomly in a $700 \mathrm{~m} \mathrm{X} 500 \mathrm{~m}$ rectangular area. Some screen shots of simulation scenarios as simulation progressed were taken. These screen shots showed the locations of each node at specific times in the course of the simulation.

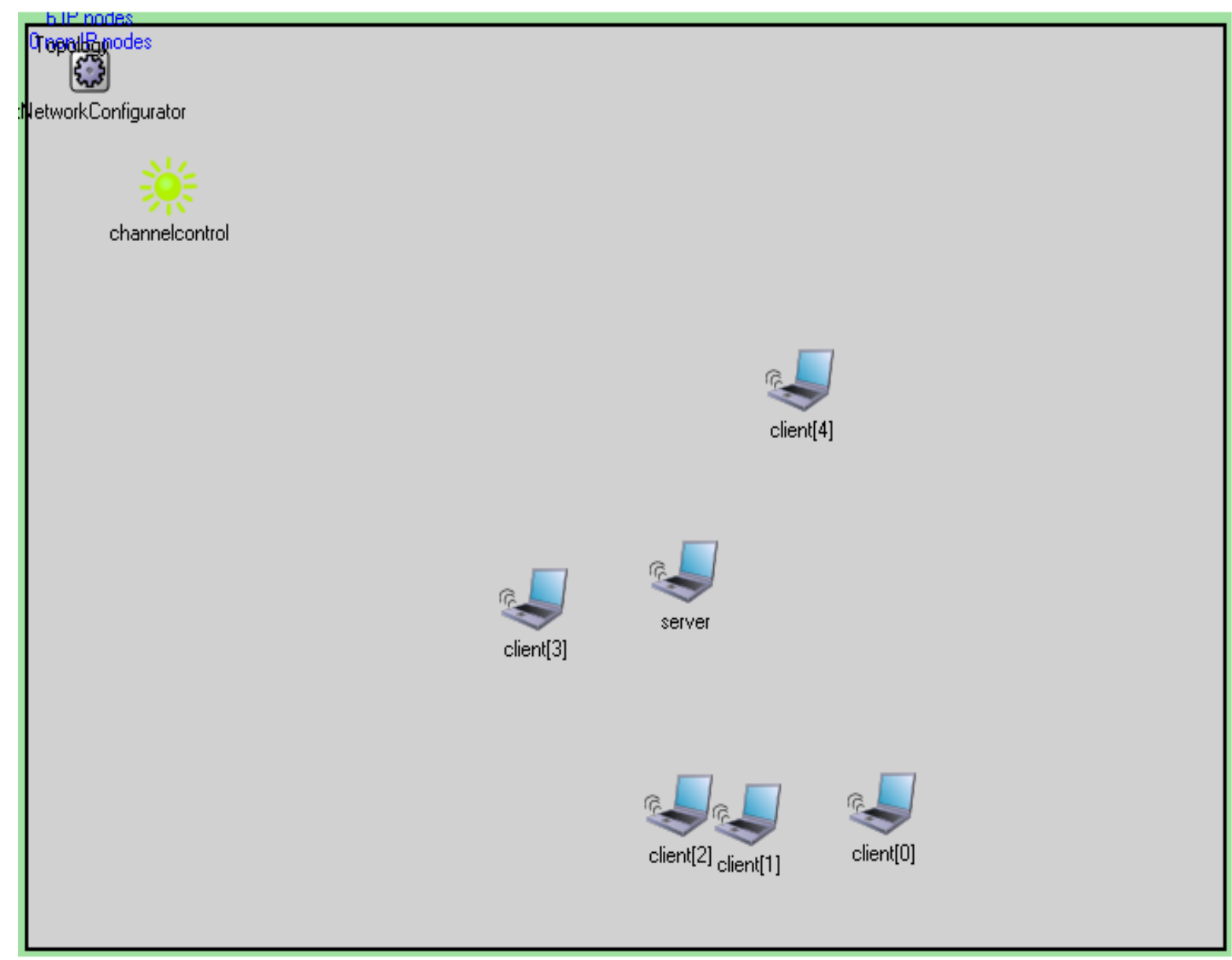

Figure 5. AODV_Tahoe Five Clients Scenario 1 at $\mathrm{t}=0$ 


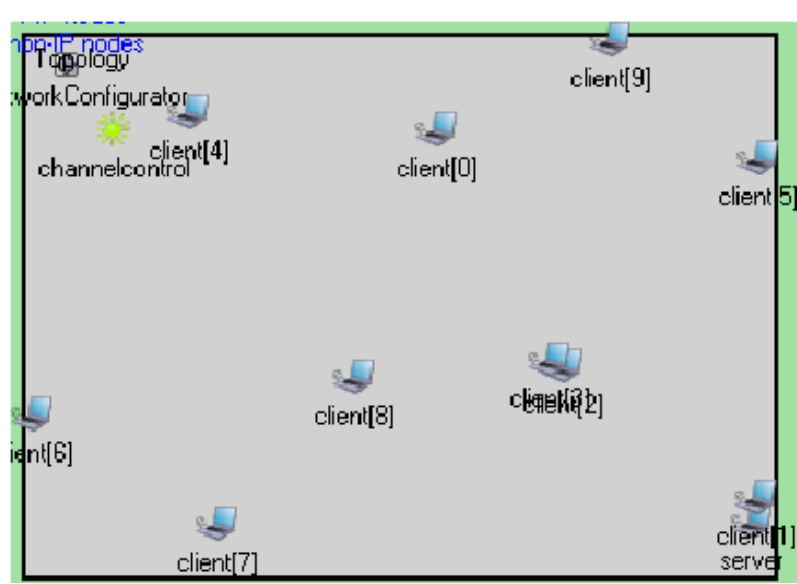

Figure 6. DSR_Reno Ten Clients Scenario 1 when $\mathrm{t}=0$

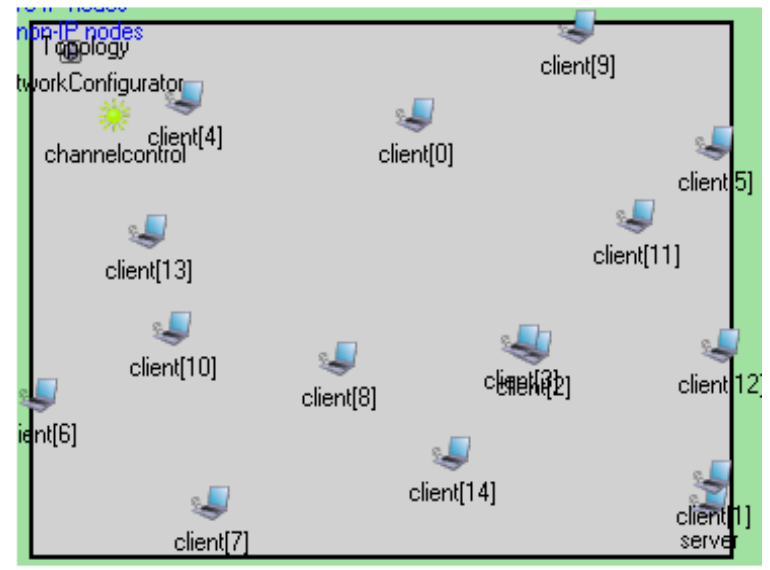

Figure 7. TORA_New Reno Fifteen Clients Scenario 1 when $\mathrm{t}=0$

\section{Results of the Simulation}

Results of the simulation were stored in the output files and exported to Microsoft Excel (spreadsheet) environment where statistical stable data were generated and bar charts/graphs were plotted. Table 1 presented the Simulation results, the corresponding graphs illustrating the results in the tables were presented in Figure 8 to Figure 9.

Table 1. Summary of simulation results

\begin{tabular}{llll}
\hline \multirow{2}{*}{ Routing protocol/TCP } & \multicolumn{2}{c}{ Average Throughput (Kbps) } \\
\cline { 2 - 4 } & 5 clients & 10 clients & 15 clients \\
\hline AODV_Tahoe & 586.679 & 177.6718 & 91.25611 \\
AODV_Reno & 565.4594 & 213.7753 & 86.09022 \\
AODV_NewReno & 440.6378 & 201.6845 & 89.11216 \\
DSR_Tahoe & 593.3919 & 76.19067 & 44.90361 \\
DSR_Reno & 593.3919 & 82.26562 & 42.59892 \\
DSR_New Reno & 487.123 & 80.25331 & 32.22977 \\
TORA_Tahoe & 890.0522 & 436.6019 & 317.7093 \\
TORA_Reno & 964.1849 & 425.026 & 307.594 \\
TORA_New Reno & 895.9946 & 500.1745 & 360.6625 \\
\hline
\end{tabular}

\section{Discussion of Results}

Mainly this study was concerned with which TCP variant perform better with what type of routing protocol. To keep clear analysis we considered each scenario separately.

\subsection{Five Clients'Scenario}

Figures 8 and 9 showed the graph and bar chart for average end to end throughput. TORA_Reno (964.1849 Kbps) had best throughput performance. 


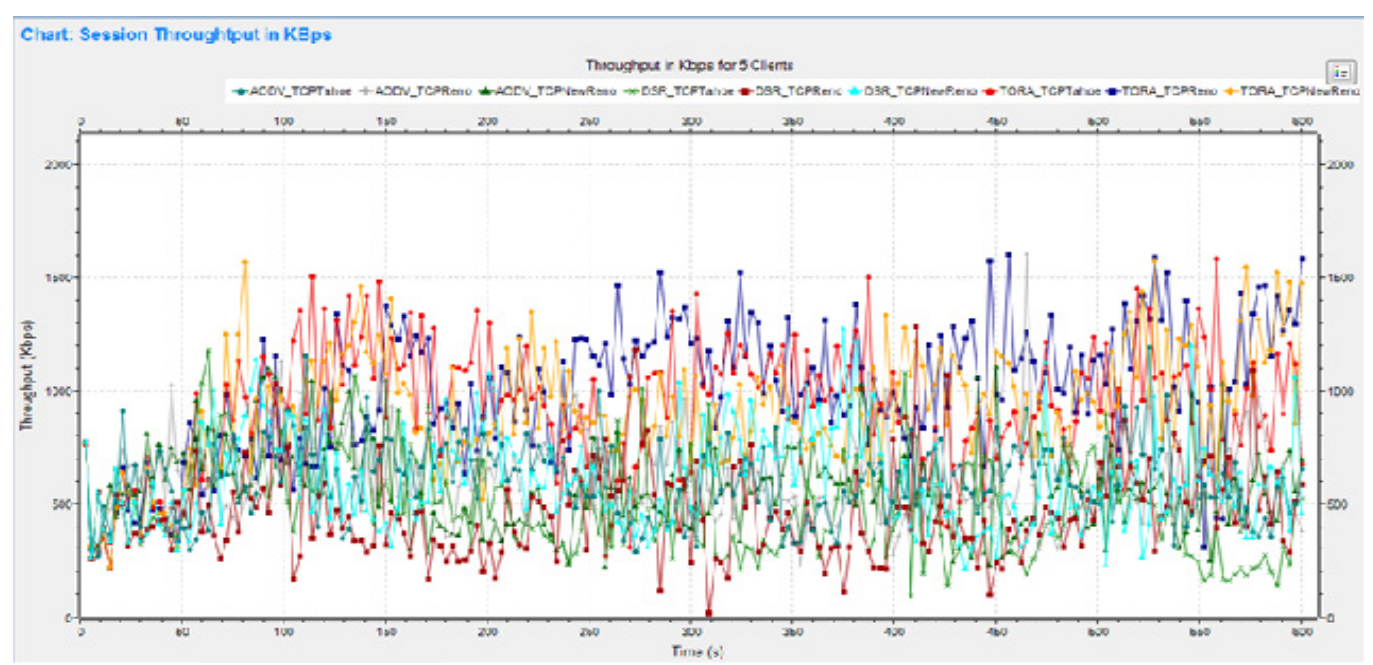

Figure 8. Overall throughput in Kbps for 5 clients

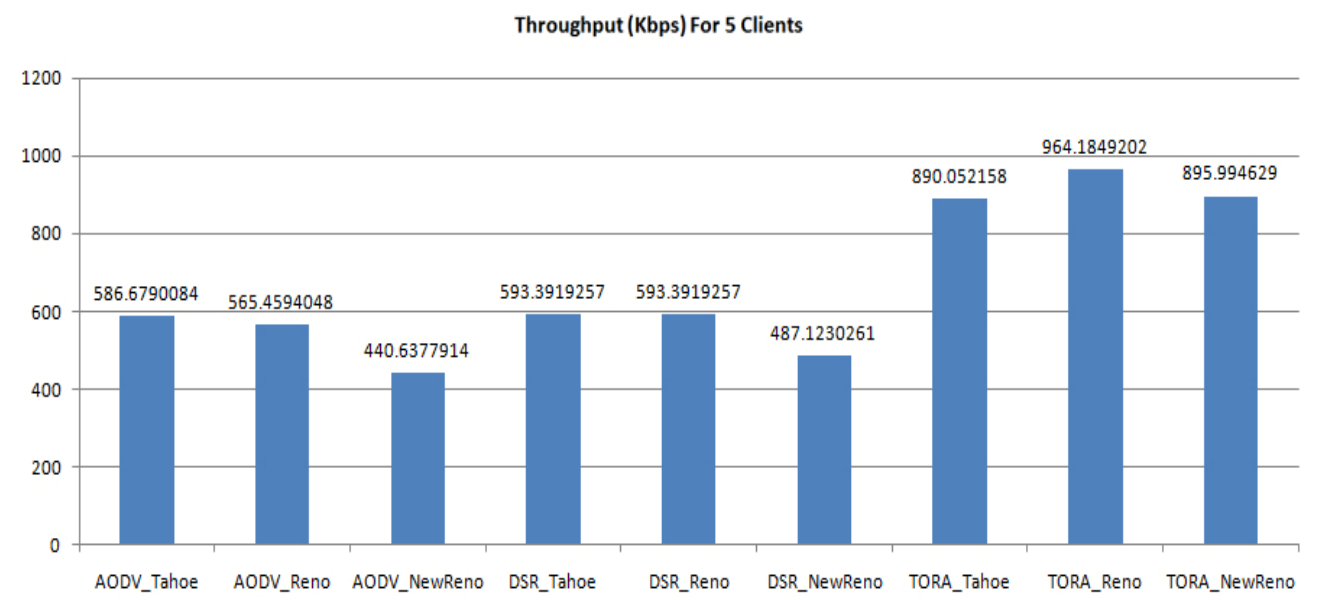

Figure 9. End to end throughput for 5 clients

\subsection{Ten Clients'Scenario}

Figures 10 and 11 showed the graph and bar chart for end to end throughput for ten clients. As numbers of clients increased, TORA_New Reno had high average end to end throughput (500.1745 Kbps). Also it was noted that as number of clients increased the throughput for all the protocol decreased particularly DSR_Tahoe, DSR_Reno and DSR_New Reno.

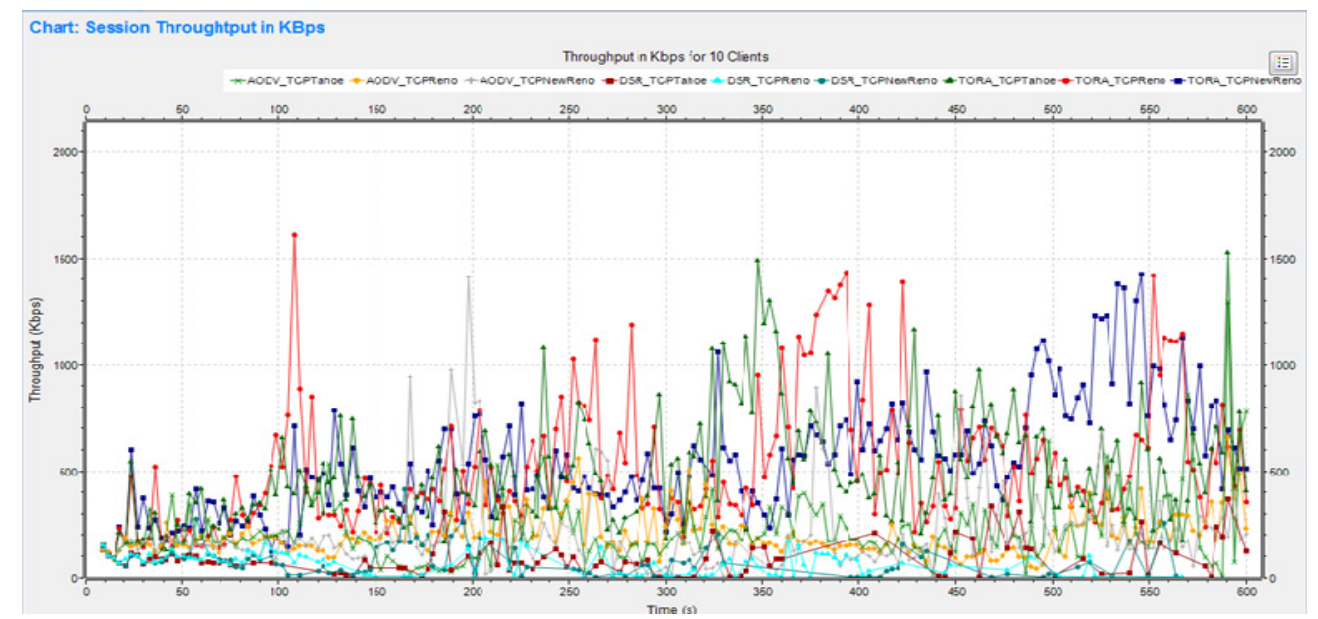

Figure 10. Overall throughput in kbps for 10 clients 


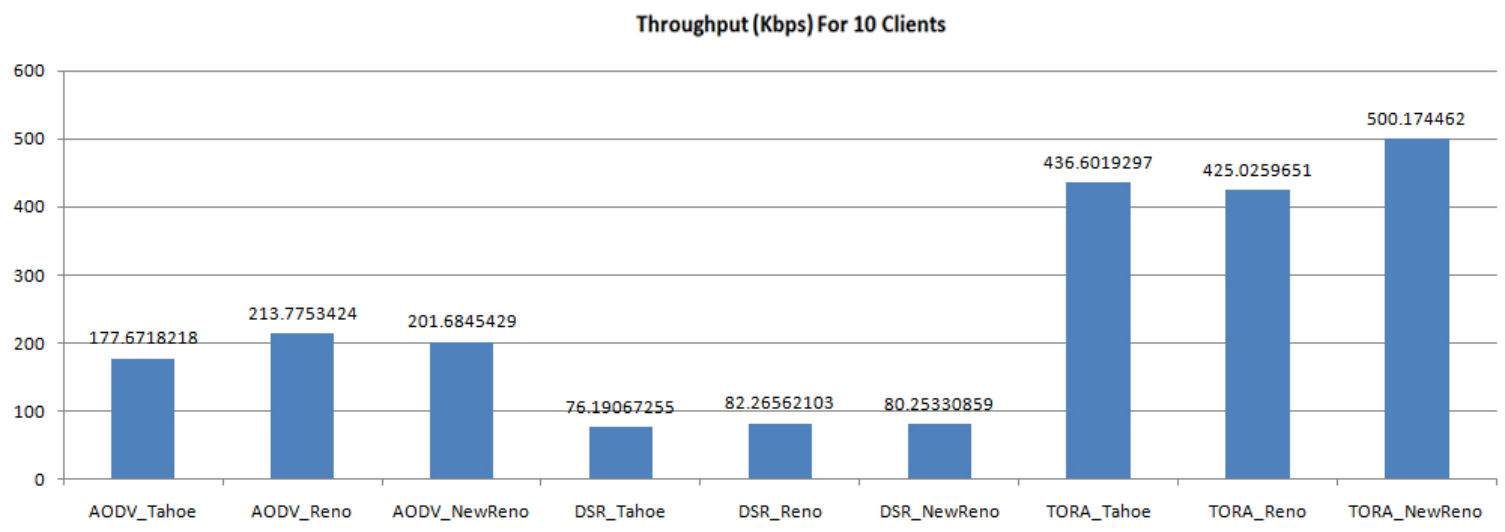

Figure 11. End to end throughput for 10 Clients

\subsection{Fifteen Clients'Scenario}

Figures 12 and 13 showed the bar chart for end to end throughput. The results showed that TORA New Reno had highest throughput (360.6625 Kbps) and DSR_New Reno had lowest throughput (32.22977 Kbps). Also it was observed that as the numbers of clients increased the throughput also decreased.

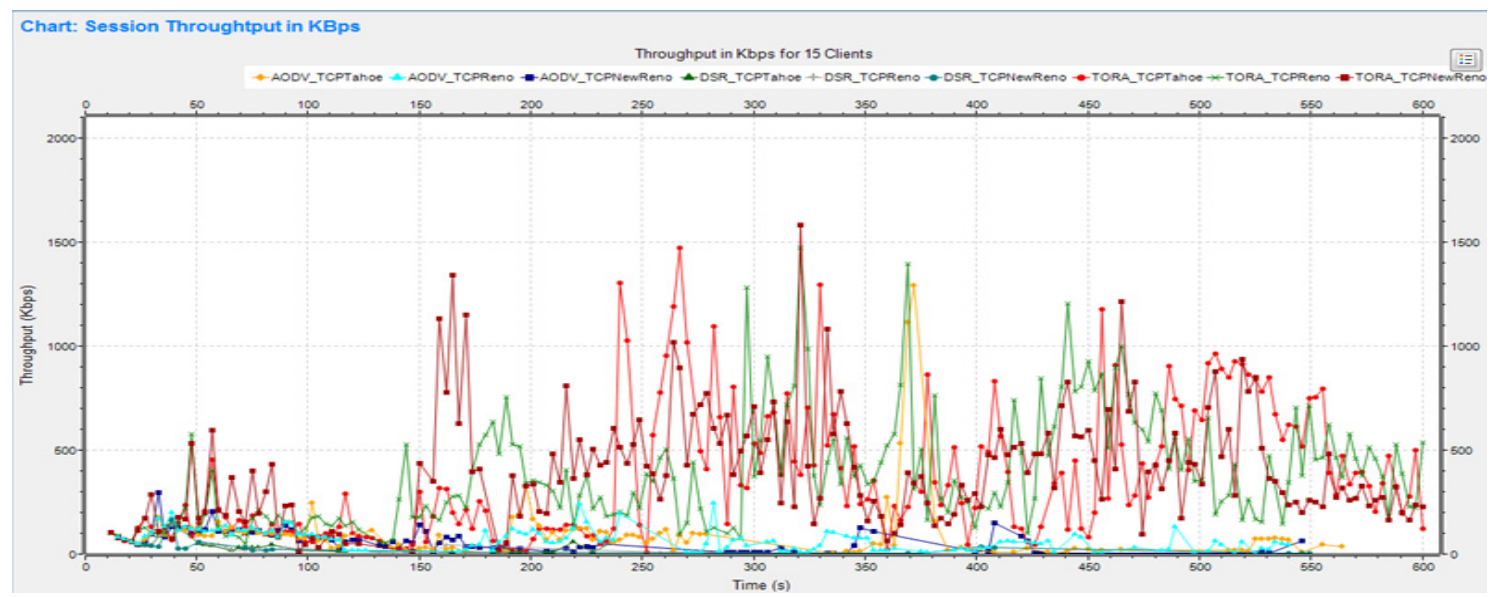

Figure 12: Overall Throughput in kbps for 15 clients

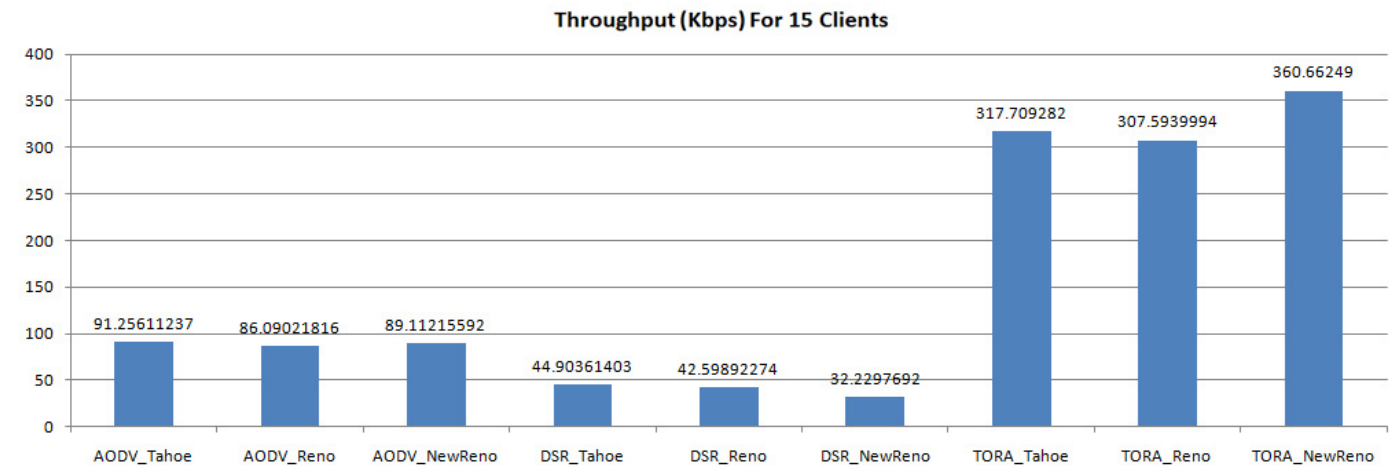

Figure 13. End to end throughput and delay for 15 Clients 


\section{Research Findings}

Mainly the researchers were concerned with end to end throughput of each variant of TCP and to find out which TCP variant performed better with what type of routing protocol.

This research adhered to the simulation results as an evident that TCP variants have minor effect on the overall results, the major dependence lies on MANET Routing Protocols. Simulation observation base on AODV, DSR and TORA clearly describe the performance evaluation through the chosen measuring parameters that when End to End Throughput is of importance, TORA is the best option among the three routing protocol. Also in a situation when End to End Delay is paramount AODV is the preferred option.

\section{Conclusion}

The simulation results showed that TCP variants have minor effect on the overall results, the major dependence lies on MANET Routing Protocols. Simulation observation base on AODV, DSR and TORA clearly describe the performance evaluation through the chosen measuring parameter that the best Routing Protocol for MANET is TORA which yielded the highest throughput with New Reno.

\section{References}

Floyd, S., \& Fall, K. (1996). Simulation Based Comparisons of Tahoe, Reno, New Reno and SACK TCP. ACM Computer Communication Review, 26(3), 5-21. http://dx.doi.org/10.1145/235160.235162

Henderson, T., Floyd, S., \& Gurtov, A. (2011). The New Reno Modification to TCP's Fast Recovery Algorithm. RCF 3782, Network Working Group, IETF draft, draft-ietf-Tcpn-rfc3782-bis-02-txt.

Ijaz, M. (2009). Transmission Control Protocol Performance Evaluation in MANET. M.Sc. Thesis (unpublished), Blekinge Institute of Technology, 12-25.

Johnson, D. B., Maltz, D. A., Hu, Y. C., \& Jetcheva, J. G. (2007). The Dynamic Source Routing. Protocol for Mobile Ad hoc Network (DSR), IETF draft-ietf-manetdsr-01.txt.

Larson, T., \& Hedman, N. (1998). Routing Protocols in Wireless Ad-Hoc Networks - A Simulation Study. M. Sc. Thesis (unpublished) in Computer Science and Engineering, Lulea University of Technology. pp. 12-35.

Liu, J., \& Singh, S. (2001). ATCP: TCP for Mobile Ad-hoc Networks. IEEE Journal in Selected Areas in Communication (JSAC), 9(7), 1300-1315. http://dx.doi.org/10.1109/49.932698

Park, V. D., \& Corson, M. S. (2001). Temporally Ordered Routing Algorithm (TORA version 1) Functional Specification. IETF Draft, draft-manet-tora-spec-04.txt.

Perkins, C. E., \& Belding-Royer, E. M. (1999). Ad hoc on Demand Distance Vector Routing. In Proc. $2^{\text {nd }}$ IEEE Workshop on Mobile Computing System and Application, New Orleans, 9-100. http://dx.doi.org/10.1109/MCSA.1999.749281

Perkins, C. E., Belding-Royer, E. M., \& Das, S. R. (2002). Ad hoc on Demand Distance Vector (AODV) Routing. IETF draft, draft-ietf-manet-aodv-10.txt.

Postal, J. (1981). Transmission Control Protocol. Request for Comments, RFC 793.

Su, M. B., Hanna, X., Aderemi, A., James, A. M., \& Bruce, C. (2007). A Performance Comparison of Wireless Ad Hoc Network Routing Protocols Under Security Attack. Proceedings of $3{ }^{\text {rd }}$ International Symposium on Information Assurance and Security, 50-55.

Vangala, S. (2003). Performance of TCP over wireless Network. M.Sc Thesis, College Of Engineering, University of South Florida, 5-14. 